\title{
Short stay observation patients: general wards are inappropriate
}

\author{
D S M Hadden, C H Dearden, L G Rocke
}

\begin{abstract}
Objective-To assess the efficiency of a short stay observation ward attached to the accident and emergency (A\&E) department of a main teaching hospital.

Methods-The study was done on 107 patients admitted to the A\&E observation ward and 107 similar patients admitted to general wards after closure of the observation ward. Patients of 13 years and over who required short term admission to hospital for observation or investigation were included.

Results-Patients admitted to the A\&E observation ward were seen sooner by a senior doctor, had fewer investigations, and had a shorter stay in hospital than similar patients admitted to the general wards.

Conclusions-The A\&E observation ward was more efficient than the general acute wards at dealing with short stay patients. (f Accid Emerg Med 1996;13:163-165)
\end{abstract}

Key terms: observation ward; general medical and surgical wards; short stay patients

The short stay (observation) ward of the accident and emergency (A\&E) department of our hospital was closed as the result of a management decision in 1993, in order to reduce costs. Patients requiring observation were subsequently admitted to the medical or surgical wards under the care of general physicians or surgeons. To assess the efficiency of the previous observation ward, the promptness of assessment, the relevance and number of observations and investigations, and the length of stay of patients who had been admitted were compared with the experience of similar patients who were admitted to the general wards.

\section{Methods}

The records of 107 patients admitted to the $A \& E$ emergency observation ward before the date of closure on 9 April 1993 were studied retrospectively to 28 January 1993 and compared with those of 107 similar patients admitted for observation to either medical or surgical wards from 9 April 1993 to 14 June 1993. The rate of admission of observation patients before 9 April 1993 was $2 \cdot 21$ patients per day and after that date 2.34 patients per day.

Normally the decision to admit a patient for observation is made by the $A \& E$ doctor (senior house officer, registrar, associate specialist, or consultant). The same medical staff were in the department over the whole period of study and identified observation patients in the same way throughout. Observation patients would not normally be considered to require more than 48 hours in hospital. After that time the patient would usually be discharged from hospital or transferred to another ward for more intensive treatment.

After the closure of the A\&E observation ward patients were admitted to medical or surgical wards under the care of general physicians or surgeons rather than the accident and emergency medical staff. The fact that they were considered to be "observation" patients was recorded on the $A \& E$ department patient record at the time of admission by the $A \& E$ medical staff. Patients admitted to the original observation ward could be categorised as medical or surgical patients, and their management compared with that of the observation patients admitted to medical and surgical wards. Patients were classified as medical or surgical according to the most significant reason for admission. Medical reasons for observation included chest pain, self poisoning, epilepsy, and social or psychiatric problems; surgical reasons included abdominal pain, head injury, minor trauma, and minor sepsis.

From the hospital records of both the observation ward and the general wards, the time lapse from admission to first examination by a senior doctor (registrar or more senior) was recorded, and the dates of admission and discharge. While they were in the observation ward some patients were diagnosed as having more serious conditions requiring transfer to regular inpatient facilities (for example, a patient admitted for observation with chest pain and later diagnosed as having a myocardial infarction): for these patients the date of transfer to the regular inpatient ward was taken to define the length of stay as an observation ward patient. Similarly, for "observation" patients admitted directly to medical or surgical wards after the closure of the observation ward, the date of diagnosis of a more serious condition requiring prolonged stay in hospital was taken to be the end of the stay as an observation patient.

Patients admitted to the observation ward or to the general wards for observation may have special investigations carried out, in addition to investigations already performed in the $A \& E$ department. Some patients have no investigations performed other than those done in the A\&E department and some patients have no investigations carried out at any time. The number of these investigations (laboratory, radiological, or other) was recorded by one of us (DSMH) for each patient from the $A \& E$ department and the hospital inpatient records. 
Table 1 Patients seen by senior doctor by day after admission, $n(\%)$

\begin{tabular}{llcl}
\hline & \multicolumn{4}{l}{ Seen by senior doctor } \\
\cline { 2 - 4 } & Yes & No & Total \\
\hline Observation ward medical & $52(98)$ & $1(2)$ & $53(100)$ \\
Observation ward surgical & $52(96)$ & $2(4)$ & $54(100)$ \\
Medical ward observation & $53(78)$ & $15(22)$ & $68(100)$ \\
Surgical ward observation & $23(59)$ & $16(41)$ & $39(100)$ \\
\hline
\end{tabular}

Table 2 Investigations

\begin{tabular}{|c|c|c|c|c|}
\hline $\begin{array}{l}\text { Number of } \\
\text { investigations }\end{array}$ & $\begin{array}{l}\text { Observation ward } \\
\text { medical patients }\end{array}$ & $\begin{array}{l}\text { Observation ward } \\
\text { surgical patients }\end{array}$ & $\begin{array}{l}\text { Medical ward } \\
\text { observation patients }\end{array}$ & $\begin{array}{l}\text { Surgical ward } \\
\text { observation patients }\end{array}$ \\
\hline 0 & 17 & 27 & 12 & 10 \\
\hline 1 & 7 & 16 & 0 & 10 \\
\hline 2 & 16 & 6 & 8 & 8 \\
\hline 3 & 5 & 3 & 12 & 3 \\
\hline 4 & 5 & 1 & 8 & 5 \\
\hline 5 & 1 & 1 & 8 & 1 \\
\hline 6 & 2 & & 4 & 2 \\
\hline 7 & & & 8 & \\
\hline 8 & & & 2 & \\
\hline 9 & & & 3 & \\
\hline 10 & & & 1 & \\
\hline 11 & & & 0 & \\
\hline 12 & & & 1 & \\
\hline 13 & & & 0 & \\
\hline 14 & & & 0 & \\
\hline 15 & & & 0 & \\
\hline 16 & & & 1 & \\
\hline Total & 91 & 46 & 285 & 72 \\
\hline Number of patients & 53 & 54 & 68 & 39 \\
\hline Average per patient & $1 \cdot 7$ & 0.9 & $4 \cdot 2$ & $1 \cdot 8$ \\
\hline
\end{tabular}

Every effort was made to obtain complete documentation of the investigations: by the nature of the acute illnesses under observation some of the results were reported by telephone and recorded by hand in the patient's records.

\section{Results}

Of the 107 patients admitted to the observation ward, $104(97 \%)$ were seen by a senior doctor within one day of admission (medical 52, surgical 52), whereas for observation patients admitted to the general wards only $76(71 \%$; medical 53, surgical 23) had a record indicating that a senior doctor had seen them within one day of admission (table 1 ).

The number of special investigations undertaken after the patients left the A\&E department is seen in table 2. Those admitted to the observation ward had a total of 137 investi-

Table 3 Length of stay in hospital, $n(\%)$

\begin{tabular}{lclll}
\hline $\begin{array}{l}\text { Length of } \\
\text { stay (days) }\end{array}$ & $\begin{array}{l}\text { Observation ward } \\
\text { medical patients }\end{array}$ & $\begin{array}{l}\text { Observation ward } \\
\text { surgical patients }\end{array}$ & $\begin{array}{l}\text { Medical card } \\
\text { observation patients }\end{array}$ & $\begin{array}{l}\text { Surgical ward } \\
\text { observation patients }\end{array}$ \\
\hline 0 & $6(11)$ & $12(22)$ & $11(16)$ & $10(26)$ \\
1 & $41(78)$ & $38(70)$ & $28(41)$ & $15(38)$ \\
2 & $5(11)$ & $3(6)$ & $12(18)$ & $6(15)$ \\
3 & & $1(2)$ & $6(9)$ & $4(10)$ \\
4 & & & $6(9)$ & $2(5)$ \\
5 & & & $1(1 \cdot 4)$ & $1(3)$ \\
6 & & $1(1 \cdot 4)$ & $1(3)$ \\
7 & & 0 & \\
8 & & $1(1 \cdot 4)$ & \\
9 & & 0 & \\
10 & & & $1(1 \cdot 4)$ & \\
11 & $52(100)$ & $54(100)$ & $68(100)$ & $39(100)$ \\
Total & & &
\end{tabular}

Table 4 Referral to outpatient clinic, $n$ (\%)

\begin{tabular}{lll}
\hline & $\begin{array}{l}\text { Referred to } \\
\text { outpatient } \\
\text { clinic }\end{array}$ & $\begin{array}{l}\text { Total } \\
\text { number } \\
\text { of patients }\end{array}$ \\
\hline Observation ward medical & $15(28)$ & $53(100)$ \\
Observation ward surgical & $15(28)$ & $54(100)$ \\
Medical ward observation & $23(34)$ & $68(100)$ \\
Surgical ward observation & $8(21)$ & $39(100)$ \\
\hline
\end{tabular}

gations, mean 1.3 per patient (medical 1.7 , surgical $0 \cdot 9$ ). Those admitted to the general wards had a total of 357 investigations, mean 3.3 per patient (medical $4 \cdot 2$, surgical $1 \cdot 8$ ). In the observation ward, 44 patients $(41 \%)$ had no investigations (medical 17, surgical 27): the greatest number for any medical patient was six and surgical patient five. In the general wards 22 of observation patients $(21 \%)$ had no investigations (medical 12, surgical 10). The greatest number of investigations for any medical ward observation patient was 16 and for surgical wards, six.

In the observation ward 105 patients (99\%) were discharged by the second day after admission ( 52 medical, 53 surgical). The longest stay was to the fourth day after admission. In the general wards, 82 of the observation patients $(77 \%)$ were discharged by the second day ( 51 medical, 31 surgical), one medical patient remaining for 11 days and one surgical patient for six days. (table 3). The observation patient who remained in hospital for 11 days was also the patient who had the greatest number of investigations (16). This elderly diabetic with previous myocardial infarction was admitted for observation of chest pain which initially resolved, and cardiac enzymes were normal for three days. Further chest pain required more investigation to confirm the diagnosis of unstable angina.

Medical patients were equally divided between men and women, but there were more women than men below 39 years of age and more men than woman above 40 years. Most medical patients were between 40 and 69 years. The male:female ratio of surgical patients was 2:1 and two thirds of these male patients were below 40 years of age. These proportions were the same in patients admitted to observation ward as in observation patients admitted to general wards.Referral to an outpatient clinic was arranged for $30(28 \%)$ of the observation ward patients (medical $25 \%$, surgical $28 \%$ ), and $31(27 \%)$ of observation patients admitted to general wards (medical $34 \%$, surgical $20 \%$ ), not including any patient who was already attending an outpatient clinic (table 4).

\section{Discussion}

The observation ward in this hospital was closed for economic reasons, but it seems from this study that admitting observation patients to general medical and surgical wards may be less cost-effective. We found that patients admitted to the observation ward were seen more rapidly by a senior doctor, had on average a shorter stay in hospital, and had fewer investigations than similar patients admitted to the general wards. Therefore it may be more efficient financially to continue admitting observation patients to a separate ward specialising in this type of patient and staffed from the $\mathrm{A} \& \mathrm{E}$ department. Although there were considerable savings by not employing nurses to staff the separate observation ward, it has proved very difficult to identify the additional costs due to admitting observation patients to the general wards, as some of these are under 
a different management structure. There was no evidence of cancelled elective surgical admission due to the presence of the additional surgical observation patients.

The need for observation beds was first recognised in 1960 by the Nuffield Review of Casualty services ${ }^{1}$ : "observation beds are really essential for a good casualty service". This recommendation was restated by the Platt report (1962), ${ }^{2}$ the Lewin report (1978) on accident and emergency services, ${ }^{3}$ and the review of accident and emergency services in the British Medical Fournal in 1979. ${ }^{4}$ There have been only occasional articles in the British medical press on this subject since then, ${ }^{5-8}$ some provoking considerable correspondence confirming the need for observation wards..$^{9-11}$ One recent study on patients with minor head injuries states that access to observation beds is more influential to management than the clinical findings, in spite of the existence of specialist guidelines. ${ }^{12}$ The British Association for Accident and Emergency Medicine has advised since 1989 that a short stay ward is an essential part of every A\&E department, and recommends one bed for every 5000 new attenders. ${ }^{13}$

An observation ward is a short stay ward, generally part of the $A \& E$ department. Its main function is to provide facilities for serial observations in well regulated surroundings. The essential qualification for admission is that the patient should not be considered to have a condition requiring intensive medical or major surgical treatment. The main groups of patients considered suitable for admission are those in whom the diagnosis is uncertain but may be clarified within 48 hours, patients with self limiting disease requiring short term observation, patients whose presenting symptoms may indicate serious illness, and patients requiring short term admission for social or psychiatric reasons. The operation of such a ward is generally safer if it is possible to admit borderline cases - this avoids discharging a patient from the $A \& E$ department if there is doubt about the development of serious illness. ${ }^{14}$ Doctors working in accident and emergency medicine develop a certain expertise in dealing with these patients, and as the ward is part of the A\&E department the medical staff are never far away and twice daily ward rounds are usual.

The A\&E department must have good rapport with other departments. Laboratory results can be obtained by telephone, and $x$ rays and ultrasound examinations should usually be obtained within hours of admission, whereas similar investigations can take days to arrange in the general wards. As the $A \& E$ department is at the interface between the hospital and the general public, its doctors are more accustomed to dealing with the whole family and the home circumstances. Social problems and situational crises can often be sorted out more rapidly in a specialised observation ward, and close liaison with social and psychiatric services is essential.

In this study $99 \%$ of patients in our observation ward were either discharged home or transferred for further treatment to another hospital ward within two days of admission, compared with only $77 \%$ of patients admitted for "observation" to the general wards. This suggests the ability to assess patients more rapidly in the observation ward and to obtain the results of investigations without delay.

The number of investigations was considerably different in the two groups of patients: an average of 1.3 per patient in the observation ward and 3.3 in the general wards. This difference is in part due to a different understanding of minimum investigations required; nearly all patients admitted to the general wards had haematological indices requested, and nearly all were normal. A great many more investigations were undertaken on patients admitted to the medical ward, often repeating on the same day tests that had already been performed in the A\&E department.

Observation wards have a rapid patient turnover, a high bed occupancy, and often a higher percentage of disturbed or difficult patients than is normally found in medical or surgical wards. The nursing staff are experienced in dealing with these problems and in taking time to communicate with these patients. Nursing input is high in such a ward and much depends on serial observations. ${ }^{14}$

Admitting "observation" patients into general wards is an inefficient use of hospital beds. These wards are less used to the rapid throughput of patients; their doctors, dealing with busy outpatient clinics or major operating lists, are not as accessible for the rapid daily management of observation-type patients. Now that hospital beds are being reduced it seems unwise to block scarce medical and surgical beds with observation patients, who may be more rapidly and therefore more costeffectively dealt with in a specific short stay ward attached to the $A \& E$ department.

1 Nuffield Provincial Hospitals Trust. Casualty services and their setting: a study in medical care. Oxford: Oxford University Press, 1960 .

2 Standing Medical Advisory Committee CHSC. Accident and emergency services (The Platt Report). London: HMSO 1962 .

Lewin W. Medical staffing and accident and emergency services. London: Joint Consultants Committee, 1978.

4 Accident and emergency services. BMF 1979;ii:837-9.

5 Dallos V, Monzas GL. An evaluation of the functions of the short stay observation ward in the accident and emergency department. BMf 1981;282:37-40.

6 Ramaiah RS, Jones DT, Pal AK. Combined short stay/day surgery/investigation unit in a district general hospital. suF 1982;284:1098-9.

7 Driscoll P, Bryce G. The use of short stay wards. A survey of 1000 admissions. Department of Health and Social Services, Health Bulletin. London, 1987:294-302.

8 Gabbay J, Mason E. Assessing a short stay ward. Senior Nurse 1987;6:20-22.

9 Morgan WJ. Functions of the observation ward in the accident and emergency department [letter]. $B M \mathcal{F}^{1981}$;

10 Abson EP. Functions of the observation ward in the accident and emergency department [letter]. BMF 1981;282:398.

11 Rutherford $W$. Functions of the observation ward in the accident and emergency department [letter]. BMF 1981 282:398-9.

12 Brown SR, Raine C, Robertson CE, Swann IJ. Managemen of minor head injuries in the accident and emergency department: the effect of an observation ward. $\mathcal{F}$ Accid Emerg Med 1994;11:144-8.

13 British Association for Accident and Emergency Medicine. Clinical Services Committee. Recommendations for Accident and Emergency Wards, 1989.

14 Rutherford WH, Nelson PG, Weston PAM, Wilson DH Accident and emergency medicine. Tunbridge Wells: Pitman Medical, 1980:145-6. 